\title{
Mixed Transcriptome Analysis Revealed the Possible Interaction Mechanisms between Zizania latifolia and Ustilago esculenta Inducing Jiaobai Stem-Gall Formation
}

\author{
Zhi-Ping Zhang ${ }^{1,2}{ }^{\mathbb{D}}$, Si-Xiao Song ${ }^{1}$, Yan-Cheng Liu ${ }^{1}$, Xin-Rui Zhu ${ }^{1}$, Yi-Feng Jiang ${ }^{1}$, Ling-Tong Shi ${ }^{1}$, \\ Jie-Zeng Jiang ${ }^{1}$ and Min-Min Miao ${ }^{1,2, *}$ \\ 1 College of Horticulture and Plant Protection, Yangzhou University, Yangzhou 225009, China; \\ zhangzp@yzu.edu.cn (Z.-P.Z.); ssx123606@163.com (S.-X.S.); lyc1234560214@sina.com (Y.-C.L.); \\ zhuxr2001@163.com (X.-R.Z.); jyf11111019@163.com (Y.-F.J.); slt20010919@163.com (L.-T.S.); \\ jzjiang@yzu.edu.cn (J.-Z.J.) \\ 2 Jiangsu Key Laboratory of Crop Genomics and Molecular Breeding, Agricultural College, \\ Yangzhou University, Yangzhou 225009, China \\ * Correspondence: mmmiao@yzu.edu.cn
}

check for updates

Citation: Zhang, Z.-P.; Song, S.-X.; Liu, Y.-C.; Zhu, X.-R.; Jiang, Y.-F.; Shi, L.-T.; Jiang, J.-Z.; Miao, M.-M. Mixed Transcriptome Analysis Revealed the Possible Interaction Mechanisms between Zizania latifolia and Ustilago esculenta Inducing Jiaobai Stem-Gall Formation. Int. J. Mol. Sci. 2021, 22, 12258. https://doi.org/10.3390/ ijms222212258

Academic Editor: Stephan Pollmann

Received: 8 October 2021

Accepted: 9 November 2021

Published: 12 November 2021

Publisher's Note: MDPI stays neutral with regard to jurisdictional claims in published maps and institutional affiliations.

Copyright: (c) 2021 by the authors. Licensee MDPI, Basel, Switzerland. This article is an open access article distributed under the terms and conditions of the Creative Commons Attribution (CC BY) license (https:/ / creativecommons.org/licenses/by/ $4.0 /)$.

\begin{abstract}
The smut fungus Ustilago esculenta infects Zizania latifolia and induces stem expansion to form a unique vegetable named Jiaobai. Although previous studies have demonstrated that hormonal control is essential for triggering stem swelling, the role of hormones synthesized by Z. latifolia and U. esculenta and the underlying molecular mechanism are not yet clear. To study the mechanism that triggers swollen stem formation, we analyzed the gene expression pattern of both interacting organisms during the initial trigger of culm gall formation, at which time the infective hyphae also propagated extensively and penetrated host stem cells. Transcriptional analysis indicated that abundant genes involving fungal pathogenicity and plant resistance were reprogrammed to maintain the subtle balance between the parasite and host. In addition, the expression of genes involved in auxin biosynthesis of $U$. esculenta obviously decreased during stem swelling, while a large number of genes related to the synthesis, metabolism and signal transduction of hormones of the host plant were stimulated and showed specific expression patterns, particularly, the expression of ZlYUCCA9 (a flavin monooxygenase, the key enzyme in indole-3-acetic acid (IAA) biosynthesis pathway) increased significantly. Simultaneously, the content of IAA increased significantly, while the contents of cytokinin and gibberellin showed the opposite trend. We speculated that auxin produced by the host plant, rather than the fungus, triggers stem swelling. Furthermore, from the differently expressed genes, two candidate Cys2-His2 (C2H2) zinc finger proteins, GME3058_g and GME5963_g, were identified from $U$. esculenta, which may conduct fungus growth and infection at the initial stage of stem-gall formation.
\end{abstract}

Keywords: Zizania latifolia; Ustilago esculenta; stem-gall formation; transcriptome; auxin; YUCCA

\section{Introduction}

Zizania latifolia Turcz. is a perennial aquatic plant that is an ancient cereal crop and has been cultivated for more than 2000 years in China [1]. However, after being parasitized by Ustilago esculenta, Z. latifolia no longer undergoes inflorescence and forms seeds but stimulates the upper parts of the stem expansion and becomes a vegetable, which is a common occurrence in China, India, and Japan in Southeast Asia [2,3]. In nature, $U$. esculenta is a number of smut fungi belonging to the basidiomycetes. Smut fungi, such as U. maydis, Sporisorium reilianum, U. hordei, Urocystis tritici, and Thecaphora solani, consistently cause devastating effects on the host plant, preventing crop growth and causing huge economic losses; smut disease is sometimes the reason for famine in any particular area or place $[4,5]$. While during the long process of artificial selection and coevolution, 
U. esculenta and Z. latifolia reached a clever balance between plant's disease resistance and fungal infection $[3,6]$, the infected stem was no longer a common disease tumor (full of black powder) but formed an edible, white swollen culm gall, which was found to be delicious and nutritious, was deeply loved by the people and was called "Jiaobai" in China [6,7]. Jiaobai cultivation has become a pillar industry in some areas of the Zhejiang and Jiangsu provinces and other regions in China, and has high economic value $[1,8]$.

For a long time, people have been trying to explore the unique mechanism underlying the formation of the fleshy stem of Jiaobai. U. esculenta, as a living trophic fungus, specifically infects Z. latifolia plants, Even in winter, smut fungi still exist in the old roots and stolon buds of the host plant. U. esculenta usually infects the buds of underground stems through vascular tissues, parenchyma or vascular bundles, after which linear, branching, aggregate, and polymerized hyphae and other changes along the intercellular space or through the cells of the host plant are observed during the transition from the seedling stage to fleshy, stem-swelling stage $[3,8]$. This process is also accompanied by a series of physiological changes, such as an increase in plant hormones, carbohydrate accumulation, and an enhancement of leaf photosynthesis during the expansion of stem galls. A large number of differentially expressed genes (DEGs) involved in material metabolism, signal transduction, plant-fungal interactions and other pathways have been found in transcriptome and proteome analyses during the different developmental stages of Z. latifolia $[3,9,10]$.

Auxin plays a variety of roles in plant growth and development. Indole-3-acetic acid (IAA), the most common auxin, not only regulates cell division, elongation and differentiation and induces the formation of roots, stems, leaves, flowers and fruits, but it also participates in tropism, such as gravitropism and phototropism, and plays an important role in emergency responses and interactions with microorganisms [11-14]. Because many pathogens produce auxin during their interaction with plants, this hormone has been thought to be important in plant disease development $[15,16]$. The role of plant hormones, especially IAA, in stem-gall expansion of Z. latifolia has long been a concern of researchers $[9,10,17]$. However, both Z. latifolia and $U$. esculenta have the ability to synthesize IAA, and the chemical structures of IAA synthesized by plants and $U$. esculenta are identical and cannot be distinguished by labeling under symbiotic conditions. Thus, in the plantfungus symbiotic system, which species is responsible for the synthesis of the auxin that triggers culm gall expansion remains unclear. In recent years, studies on $U$. maydis and other fungi have shown that IAA is mainly synthesized through the IPyA (indole-3-pyruvic acid) and IAM (indole-3-acetamide) pathways $[18,19]$. The key enzymes in the IPyA pathway include tryptophan aminotransferase (TAM), indole-3-pyruvate decarboxylase (IPDC) and indole-3-acetaldehyde dehydrogenase (IAD); the IAM pathway includes L-amino acid oxidase (iaaM) and N-acetylthanolamine amidohydrolase (iaaH) $[20,21]$. On the other hand, the tryptophan-dependent auxin biosynthesis pathway is essential for plant developmental processes, and TRYPTOPHAN AMINOTRANSFERASE OF ARABIDOPSIS (TAA) and YUCCA (a flavin monooxygenase) are two important catalytic enzymes [22,23]. The difference in the IAA biosynthesis pathway between $U$. esculenta and plants could provide the possibility of distinguishing the producer of IAA in the initial formation of Jiaobai stem gall. Moreover, the YUCCA protein is the rate-limiting enzyme in the Trpdependent IAA biosynthesis pathway, and the YUCCA gene has been studied extensively in many plants, such as Arabidopsis, maize (Zea mays), potato (Solanum tuberosum), and rice (Oryza sativa), by identification and analysis at the whole-genome level [24-27]. Compared with the above-mentioned plants, our understanding of the YUCCA family in Z. latifolia is still limited.

To comprehensively understand plant-pathogen interactions, it is valuable to monitor the gene expression profiles of both interacting organisms simultaneously in the same infected plant tissue using the transcriptome [28-30]. This approach was used to investigate the DEGs in a variety of host plants and pathogens, such as in wheat defense and Azospirillum brasilense attack, the interaction between rice and Magnaporthe oryzae, and Brassica napus and Sclerotinia sclerotiorum $[29,31,32]$. To better understand the potential 
molecular mechanisms of Z. latifolia-U. esculenta interactions and the role of plant hormones during the formation of stem galls, we performed dual (plant and fungus) RNA-seq transcriptional profiling of the DEGs of both Z. latifolia and U. esculenta and investigated the contents of phytohormones in the initial stage of stem-gall formation. We further identified the YUCCA gene family in the host using bioinformatics methods and analyzed the expression pattern of YUCCA gene family members when triggering the formation of stem galls. In addition, the pathogenicity genes in $U$. esculenta and plant-resistance genes in $Z$. latifolia, and $U$. esculenta differentially expressed transcripts factors were also analyzed to understand the role of both the plant and the fungus in the gall formation.

\section{Results}

\subsection{Distribution of U. esculenta in the Initial Trigger of Stem-Gall Formation of Z. latifolia}

At 10 days before culm gall formation $(-10 \mathrm{~d})$, the length of the three newly grown leaves (leaf 1 , leaf 2 and leaf 3 ) were almost the same, and the junctions of the leaf sheath and leaf 1, leaf 2 and leaf 3 were obviously separated (Figure 1A, marked by red circles); when the outer leaves were stripped, the tops of the stem were only a very small and short growth point, and no obvious nodes were observed (Figure 1C). Upon the initial trigger of culm gall formation $(0 \mathrm{~d})$, the height of the central leaf (leaf 1 ) was lower than that of the outer leaf (leaf 2 and leaf 3), and its width became wider and the color became light green; the junctions of the leaf and the leaf sheath of leaves 1-3 gradually approached to form a line, and the nodes and internodes could be clearly observed (Figure 1B,D). These morphological changes provided useful cues for us to sample the stem apex at certain growth stages.

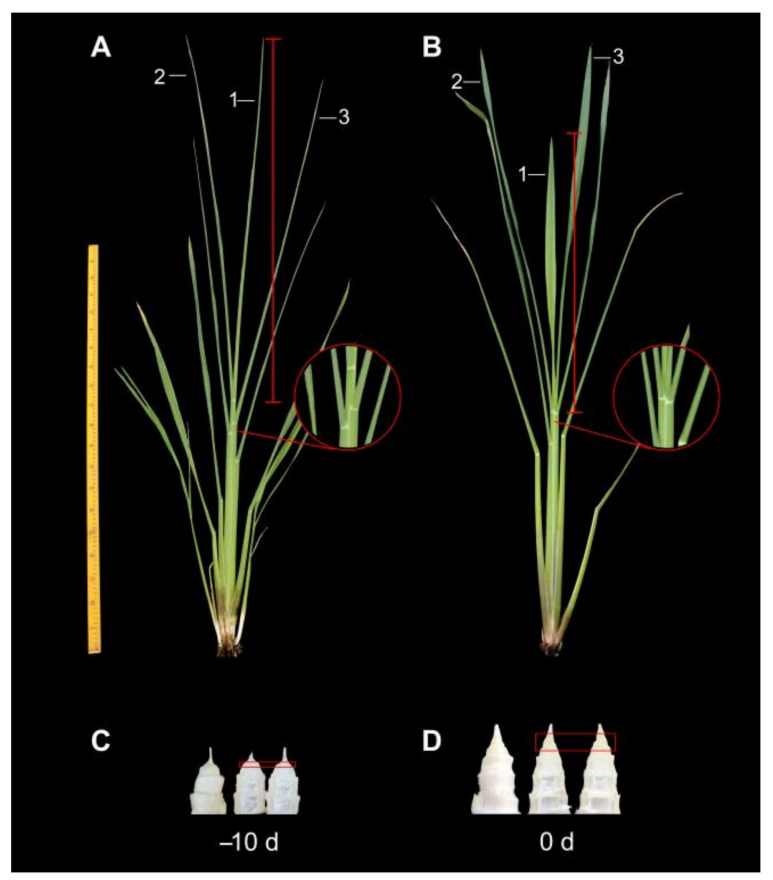

Figure 1. Photographs showing the morphology of plants and stem galls of Jiaobai. (A,B) External morphological characteristics of Jiaobai plants. (C,D) Longitudinal section of stem gall. -10 d, 10 days before stem-gall formation; $0 \mathrm{~d}$, the initial stage of stem-gall formation; red circles, the junction of leaf sheath and leaf. Red frame, the tissue for the mixed transcriptome analysis of Z. latifolia and U. esculenta.

U. esculenta hyphal distribution at $-10 \mathrm{~d}$ and $0 \mathrm{~d}$ were observed. U. esculenta hyphae were rare in the $-10 \mathrm{~d}$ and were focused at the nodes; most hyphae were short and rod-shaped, and a few were elongated (Figure 2A(a,b)). The initial swollen stem gall was divided into five parts: stem apex, first node, second node, internode, and bottom 
(Figure 2A(c)). The distribution of hyphae in the stem apex was small and compact, with a few hyphae (Figure 2A(d)). Below the apex, the number of hyphae began to increase significantly, and most of them were clustered at the first node of the stem gall (Figure 2A(e)). The number of small hyphal clusters in the second node was large and dense (Figure 2A(f)). The internode cells began to grow and gradually formed cavities, the area of small hyphal clusters in this region became larger, and the hyphae extended through a number of cells (Figure $2 \mathrm{~A}(\mathrm{~g})$ ). At the bottom of the gall, the number and areas of hyphal clusters decreased, and the cavities became increasingly larger (Figure 2A(h)). Under scanning electron microscopy, a small number of round or irregular spores were sporadically distributed in the nonswollen tissue, while a large number of hyphae were dense and vigorous, showed a network and winding pattern, and tended to extend to the interior of the host tissue at $0 \mathrm{~d}$ of stem-gall formation (Figure 2B).


Figure 2. Observation of U. esculenta hyphal distribution in Z. latifolia tissue. (A) Paraffin sections showing the U. esculenta hyphal distribution in Z. latifolia stem apexes. (a,b). Longitudinal sections of the stem apex (a) and U. esculenta hyphal distribution (b) at $-10 \mathrm{~d}$ before the stem began swelling $(-10 \mathrm{~d})$, bar $=200 \mu \mathrm{m}$. (c). Five tissue parts of the initial swollen stem tissue $(0 \mathrm{~d})$. ( (d-h). Distribution of $U$. esculenta hyphae. 1, (d) stem apex, 2, (e) first node, 3, (f) second node, 4, (g) internode, and 5, (h) bottom, respectively. bar $=100 \mu \mathrm{m}$. red arrows, U. esculenta. (B) Scanning electron micrographs of U. esculenta hyphae in Z. latifolia tissue. $(\mathbf{a}, \mathbf{b})-10 \mathrm{~d}$ before stem-gall formation. (c,d) $0 \mathrm{~d}$ of the initial stage of stem-gall formation. (a,c) and (b,d) bar $=10 \mu \mathrm{m}$ and $2 \mu \mathrm{m}$. Red and green arrows represent $U$. esculenta and Z. latifolia tissue, respectively. Green letters P, Z. latifolia; red letters U, U. esculenta.

\subsection{General Features of the $U$. esculenta and Z. latifolia Transcriptomes}

To identify the genes expressed in fungi and plants upon the initial trigger of culm gall formation of $Z$. latifolia, we selected the early stage of swollen stem, i.e., $0 \mathrm{~d}$ of culm gall formation $(0 \mathrm{~d})$, and used $10 \mathrm{~d}$ before culm gall formation $(-10 \mathrm{~d})$ as the control. In this project, a total of six samples were tested using the BGISEq-500 platform, and each sample produced $15.25 \mathrm{~Gb}$ of clean bases on average. The first versions of the Z. latifolia genome database (ASSH00000000.1) and U. esculenta genome database (JAAKGJ010000000) were selected as reference sequences. The average ratio of the samples to the Z. latifolia and $U$. esculenta genomes was $84.03 \%$ and $4.76 \%$, and the average ratio of the gene set was $66.82 \%$ and $3.56 \%$, respectively (Table 1 ). The correlation coefficient analysis of the samples showed a clear distinction between the transcriptomes of $-10 \mathrm{~d}$ before and $0 \mathrm{~d}$ of stem-gall formation (Figure S1). The gene mapping to Z. latifolia showed a greater abundance at $-10 \mathrm{~d}$ than at $0 \mathrm{~d}$ (the total mapping of the gene set was $67.5 \%$ at $-10 \mathrm{~d}$ and $66.1 \%$ at $0 \mathrm{~d}$ ), while the results from $U$. esculenta showed the opposite pattern. The total mapping of the gene set at $0 \mathrm{~d}$ was 1.47-times greater than that at $-10 \mathrm{~d}$ (Table $\mathrm{S} 1$ and Figure 3 ). 
Table 1. Statistics for the transcriptome analysis of the Z. latifolia-U. esculenta interaction in the initial stage of stem-gall formation.

\begin{tabular}{ccc}
\hline Statistics & U. esculenta & Z. latifolia \\
\hline Total clean reads $(\mathrm{Gb})$ & 15.25 & 15.25 \\
Average mapping ratio of genome sequence (\%) & 4.76 & 84.03 \\
Average mapping ratio of gene set (\%) & 3.56 & 66.82 \\
Total gene number & 6330 & 40,856 \\
Known gene number & 6319 & 37,622 \\
Novel gene number & 11 & 3234 \\
Total novel transcript & 1345 & 36,704 \\
Coding transcript & 1013 & 28,273 \\
Noncoding transcript & 332 & 8431 \\
Novel isoform & 1002 & 24,993 \\
Novel transcript & 11 & 3280 \\
\hline
\end{tabular}

A

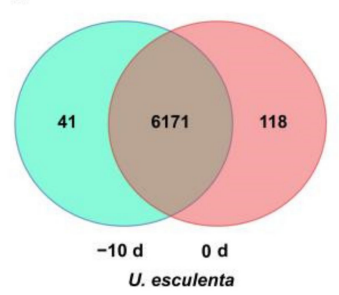

B

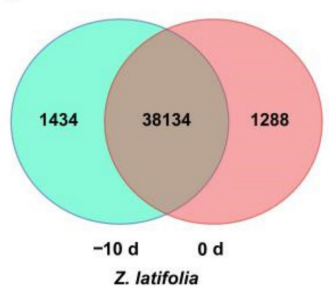

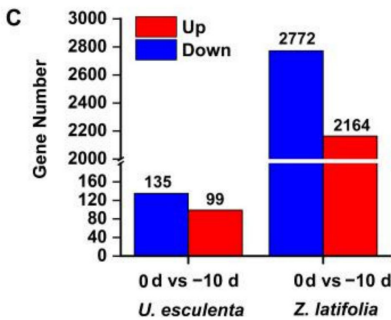

Figure 3. Transcriptome profiles of the gene expression patterns of Z. latifolia and $U$. esculenta in the initial stage of stem-gall formation. The number of common genes, specific genes of $U$. esculenta (A) and Z. latifolia (B), and DEGs in both interacting organisms (C) between $-10 \mathrm{~d}$ and $0 \mathrm{~d}$ of stem-gall formation.

A total of $6330 \mathrm{U}$. esculenta genes were present in the interacting transcriptome, among which 6319 were known and 11 were novel. A total of 6171 occurred at both $10 \mathrm{~d}$ and $0 \mathrm{~d}$, among which 41 genes were known in the $-10 \mathrm{~d}$ samples and 118 genes were known in the $0 \mathrm{~d}$ samples (Figure 3A). Furthermore, 234 DEGs were identified upon Z. latifolia enlargement, and 99 genes were upregulated and 135 genes were downregulated in the $0 \mathrm{~d}$ compared with the $-10 \mathrm{~d}$ samples (Figure $3 \mathrm{C}$ ).

When the Z. latifolia genome was used as a reference, the total number of expressed genes was 40,856, including 37,622 known genes and 3234 predicted new genes; a total of 36,704 new transcripts were detected, among which 24,993 belonged to new alternative splicing subtypes of known protein-coding genes, 3280 belonged to transcripts of new protein-coding genes, and the remaining 8431 belonged to long noncoding RNA (Table 1). There were 38,134 common genes in both samples and 1434 and 1288 unique genes at $-10 \mathrm{~d}$ and $0 \mathrm{~d}$, respectively (Figure $3 \mathrm{~B}$ ). Compared with the $-10 \mathrm{~d}$ samples, there were 4936 DEGs, 2164 upregulated genes and 2772 downregulated genes in the $0 \mathrm{~d}$ samples (Figure 3C). Further analysis of the Gene Ontology (GO) and the KEGG pathway of DEGs in U. esculenta and Z. latifolia can be seen in the Supplementary Materials (Figures S2-S5, and Tables S2-S6).

\subsection{Analysis of Pathogenicity Genes in U. esculenta and Plant Resistance Genes in Z. latifolia}

The PHI (pathogen-host interactions) database integrates a large amount of experimental gene data for known virulence, lethality and effector functions of pathogens infecting animals, plants and fungi. In this study, we used DIAMOND v0.8.31 (Max Planck Institute for Developmental Biology, Tübingen, Germany) to align genes to the PHI base database for annotation. Using a query coverage $\geq 50 \%$ and identity $\geq 40 \%$ as filter parameters, a total of 71 DEGs demonstrated homology with known pathogenicity genes. Among them, 44 DEGs were considered to be predictive pathogenic factors of U. eculenta, including 4 DEGs for increased virulence, 7 DEGs for lost pathogenicity, 30 DEGs for reduced 
virulence, and 2 DEGs for effectors. Concurrently, 3 DEGs and 1 DEG were found to be homologous with the PHI genes having lethal properties and targeted resistance to chemicals, respectively. It is worth noting that the expression levels of three DEGs, GME3251_ $g$, GME3196 $g$ and GME1171_g, which were necessary for the survival of the strain, were all significantly lower in the initial stage of culm gall formation than at $10 \mathrm{~d}$ before gall enlargement. In addition, most of the DEGs with increased virulence such as GME4426_g, GME6815 $g$ and GME6967 $\_$, also showed the same expression pattern (Figure 4).



Figure 4. Prediction of pathogenicity-related genes based on the PHI database. Chemical target: resistance to a chemical, in which the mutation of the gene leads to resistance to certain drugs; Effector (plant avirulence determinant); Increased virulence, Hypervirulence; Lethal, the gene is necessary for the survival of the strain; Loss of pathogenicity, deletions of the gene do not cause disease; Reduced virulence, the deletion mutant is less virulent; Unaffected pathogenicity, the gene does not affect the pathogenicity of the pathogen.

Plant resistance genes play an important role in the interaction between plants and pathogens. There were 368 DEGs in the initial stage of stem-gall formation, including 31 DEGs in the combination of coiled coil domain, nucleotide binding site and leucine-rich repeat (CC-NB-LRR, or CNL), 104 DEGs in the combination of nucleotide binding site and leucine-rich repeat (NB-LRR, or NL), 28 DEGs in the combination of Toll-interleukin receptor-like domain, nucleotide binding site and leucine-rich repeat (TIR-NB-LRR, or $\mathrm{TNL}), 73 \mathrm{DEGs}$ in the combination of receptor serine-threonine kinase-like domain and extracellular leucine-rich repeat (ser/thr-LRR, or RLP), and 22 DEGs in the combination of kinase domain and extracellular leucine-rich repeat (Kin-LRR, or RLK), which represented the domain types of plant disease-resistance genes with more DEGs (Figure S6).

\subsection{Hormonal Analysis during Stem-Gall Formation in Z. latifolia}

\subsubsection{Hormone Content Analysis}

The role of phytohormones in the gall emlargement of "Jiaobai" has been widely reported. Therefore, analysis of hormone content at the early stage of stem-gall formation was conducted. The hormone content assay in the apical stem meristem indicated that the free indole-3-acetic acid (IAA) content and IPyA content increased significantly at $0 \mathrm{~d}$ compared with $-10 \mathrm{~d}$, while the contents of six other hormones, zeatin (ZT), GA $1, \mathrm{GA}_{3}$, ABA, JA and SA, decreased by $31.5 \%, 40.3 \%, 29.6 \%, 57.5 \%, 64.1 \%$ and $53.7 \%$, respectively (Figure 5). These results further indicate that IAA should play a key role in the induction of fleshy stem enlargement in Z. latifolia. 

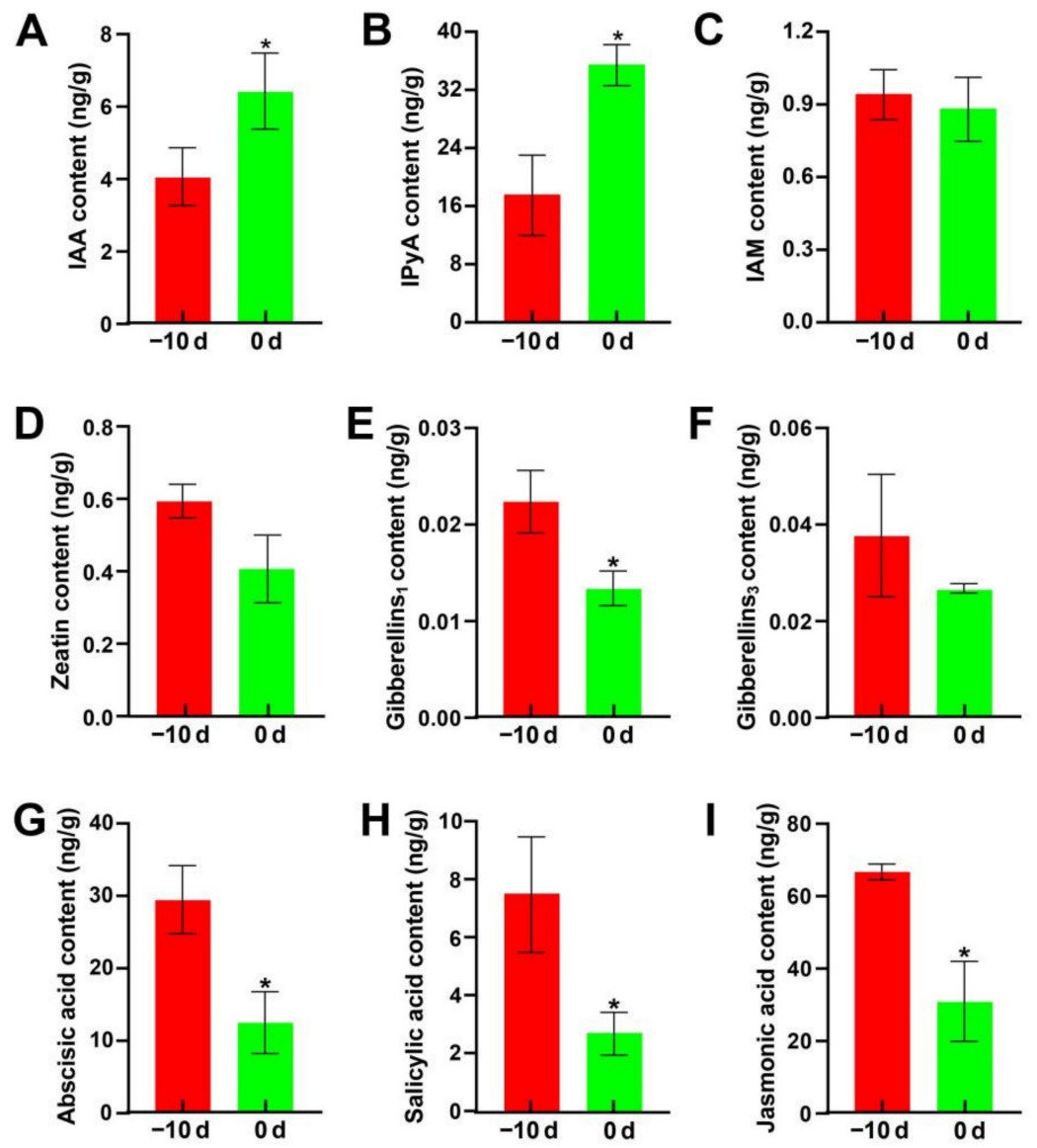

Figure 5. Hormone content at the early stage of stem-gall formation. (A-I) IAA, IPyA, IAM, ZT, GA 1 , $\mathrm{GA}_{3}, \mathrm{ABA}, \mathrm{SA}$ and JA. Asterisks $\left({ }^{*}\right)$ indicate significant differences $(p<0.05)$ between same form of hormone content in the different stage of stem-gall formation.

\subsubsection{DEGs Involved in Hormone Metabolism and Signal Transduction}

Furthermore, all the DEGs involved in hormone metabolism and signal transduction of U. esculenta and Z. latifolia during stem-gall formation were also investigated. Tryptophan is an essential precursor of many indoles and other secondary metabolites, and anthranilate synthase (TrpE) is a key regulatory enzyme in the synthesis of tryptophan, indole-3-acetic acid, and indole alkaloids. In $U$. esculenta, we found that the expression of anthranilate synthase encoded by GME3221_g (annotated in the KEGG pathway: phenylalanine, tyrosine and tryptophan biosynthesis) decreased significantly. Furthermore, expression of the genes encoding enzymes involved in auxin synthesis (annotated in the KEGG pathway: tryptophan metabolism), such as GME1810_g encoding tryptophan aminotransferase and GME621_g and GME6394_g encoding aldehyde dehydrogenases, was significantly decreased in the initial stage of culm gall formation. This result suggested that auxin synthesis in fungi was less efficient during the formation of Z. latifolia (Table S4).

In Z. latifolia, the results revealed 149 DEGs associated with the auxin (IAA), cytokinin (CTK), gibberellin (GA), abscisic acid (ABA), salicylic acid (SA) and jasmonic acid (JA) pathways (Figure 6 and Table S7). Among the six hormones, the auxin synthesis and signal transduction pathways had the largest number of DEGs, where the expression of 36 of the 43 differential genes was upregulated, and only 6 genes were downregulated, indicating auxin should play a pivotal role in the gall formation. In the cytokinin group, however, most DEGs were downregulated, accounting for $62.5 \%$. The other DEGs were related to gibberellin, abscisic acid and salicylic acid and jasmonic acid metabolism and signal transduction pathways, which encompassed 15, 11, 11 and 7 upregulated DEGs and 12, 11, 8 and 8 downregulated DEGs, respectively. Among 149 DEGs, the most upregulated and downregulated genes were Zlat_10044672 (auxin-induced protein, 15A- 
like) and Zlat_10015168 (a putative bZIP transcription factor in the salicylic acid pathway), respectively (Table S7). Notably, according to the sequence analysis, among the three genes annoatated in the auxin biosynthesis pathway, the only downregulated gene (Zlat_10023244, annoated as cytochrome P450 77A3) does not belong to the YUCCA family, while the expression level of another typical YUCCA gene Zlat_100038559 was significantly increased. These results further suggest that auxin was important for gall formation. The annotation and the Log2-fold changes of involved genes are listed in Table S7.
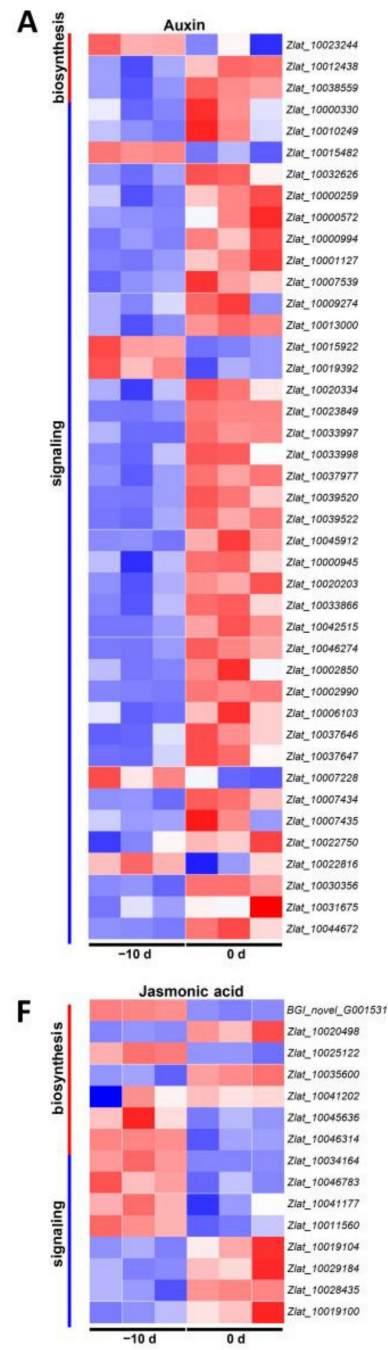
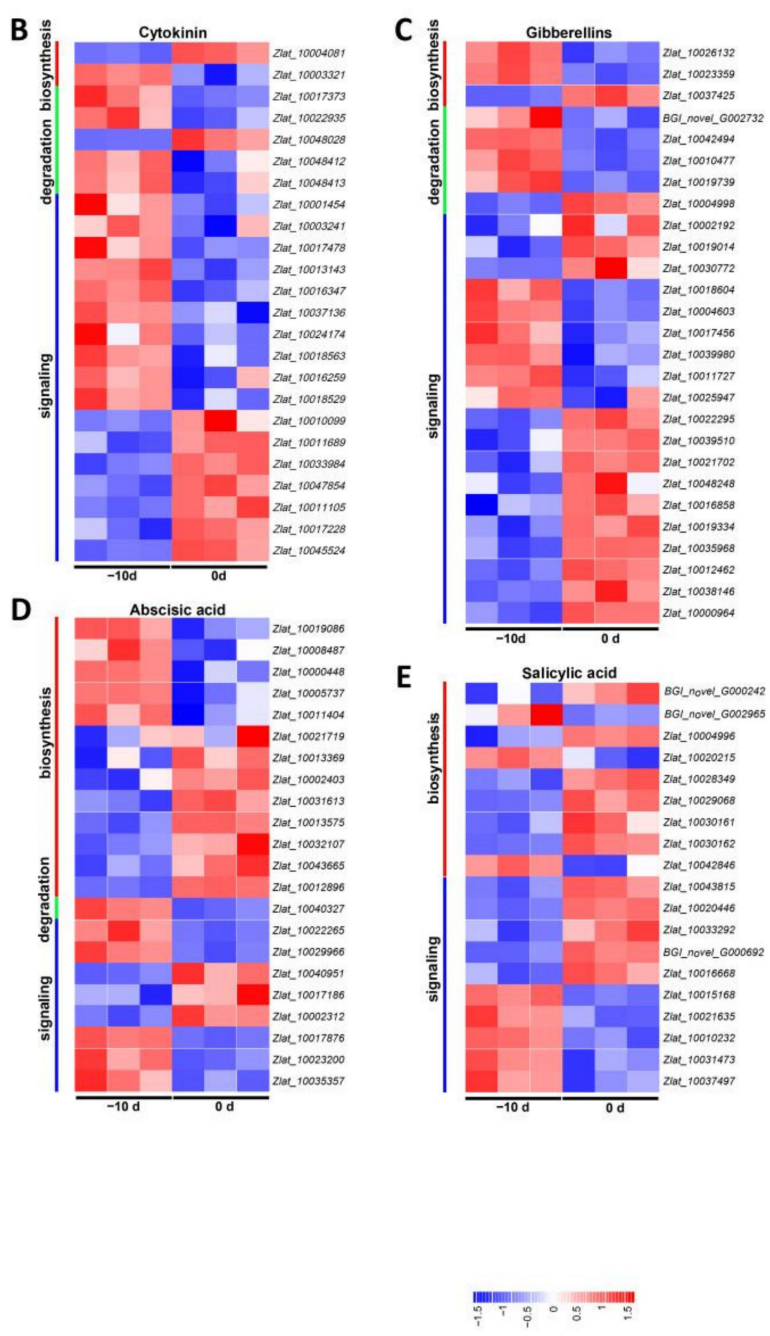

Figure 6. Expression profiles of DEGs related to hormone metabolism and signals between the two stages ( $-10 \mathrm{~d}$ and $0 \mathrm{~d}$ ) of stem-gall formation based on the Z. latifolia genome in RNA-Seq. (A-F) DEGs for auxin, cytokinin, gibberellin, abscisic acid, salicylic acid and jasmonic acid. Red, green and blue lines represent biosynthetic degradation and signal transduction DEGs, respectively.

\subsection{Auxin Regulation of Stem-Gall Formation in Z. latifolia}

2.5.1. Genes Encoding Enzymes Involved in IAA Biosynthesis in U. esculenta and Z. latifolia

Using BLASTP, we obtained 2 TAM (GME1810_g, GME6257_g), 1 IPDC (GME2840_g), 4 IAD (GME621_g, GME4730_g, GME6394_g, GME6395_g), 1 IaaM (GME5774_g), 2 iaaH (GME5840_g, GME6749_g) and 2 Nitrilase (GME1046_g, GME2826_g) from U. esculenta and 4 TAA (Zlat_10020352, Zlat_10036150, Zlat_10029220, Zlat_10033167) and 1 IAMH (Zlat_10032813) from Z. latifolia (Table S8). The YUCCA contained the conserved domains of FMO (FxGxxxHxxxy), FAD (GxGxG) and NADPH binding (GxGxG). Therefore, to identify the YUCCA gene family of Z. latifolia, we not only used the Arabidopsis YUCCA protein sequence for BLASTP but also analyzed the basic domain. In addition, because of 
the unusual FMO-identifying motifs (FxSxxxHxxxY) in Arabidopsis YUCCA1, we also identified these unusual motifs in all Z. latifolia genes. Finally, a total of 12 genes, Zlat_10027383, Zlat_10004518,Zlat_10004101, Zlat_10029766, Zlat_10013524, Zlat_10029560, Zlat_10017358, Zlat_10020875, Zlat_10038559, Zlat_10020360, Zlat_10002766, and Zlat_10020876, were identified as the Z. latifolia YUCCA gene and named ZLYUCCA1-12 (Tables S8 and S9).

2.5.2. Structural and Functional Characteristic Analysis of the YUCCA Gene Family in Z. latifolia

The 11, 14 and 8 YUCCA protein sequences from Arabidopsis, rice and potato were used as references to construct a phylogenetic tree with 12 YUCCA protein sequences of Z. latifolia plants in order to explore the phylogenetic relationship of the YUCCA gene family in Z. latifolia (Figure 7A, Table S9). The results showed that the Z. latifolia YUCCA gene family was mainly divided into four subfamilies, ZIYUCCA 1, ZIYUCCA 2,3,4, ZlYUCCA 6,7 and ZlYUCCA 5, 8, 9, 10, 11, 12. In addition, the phylogenetic tree showed that Z. latifolia was closely related to rice but distantly related to Arabidopsis and potato. Structural analysis of the YUCCA gene family in Z. latifolia showed that the gene structure was complex, and the number of exons and introns was irregular, with 2-8 and 1-7, respectively (Figure 7B). Furthermore, the complete protein sequences of YUCCA family proteins in Z. latifolia were aligned, and the three conserved domains FMO (FxGxxxHxxxY), FAD (GxGxG) and NADPH binding (GxGxG), were labeled. Among the 12 YUCCAs, ZlYUCCA1 (Zlat_10027383) contained a nonstandard FMO motif, the G mutation in FXGXXXHXXXY was $S$, and the similarity between the amino acid sequence of this gene and OsYUCCA1 was $93.675 \%$ (Figure $7 \mathrm{~A}, \mathrm{C})$.

A
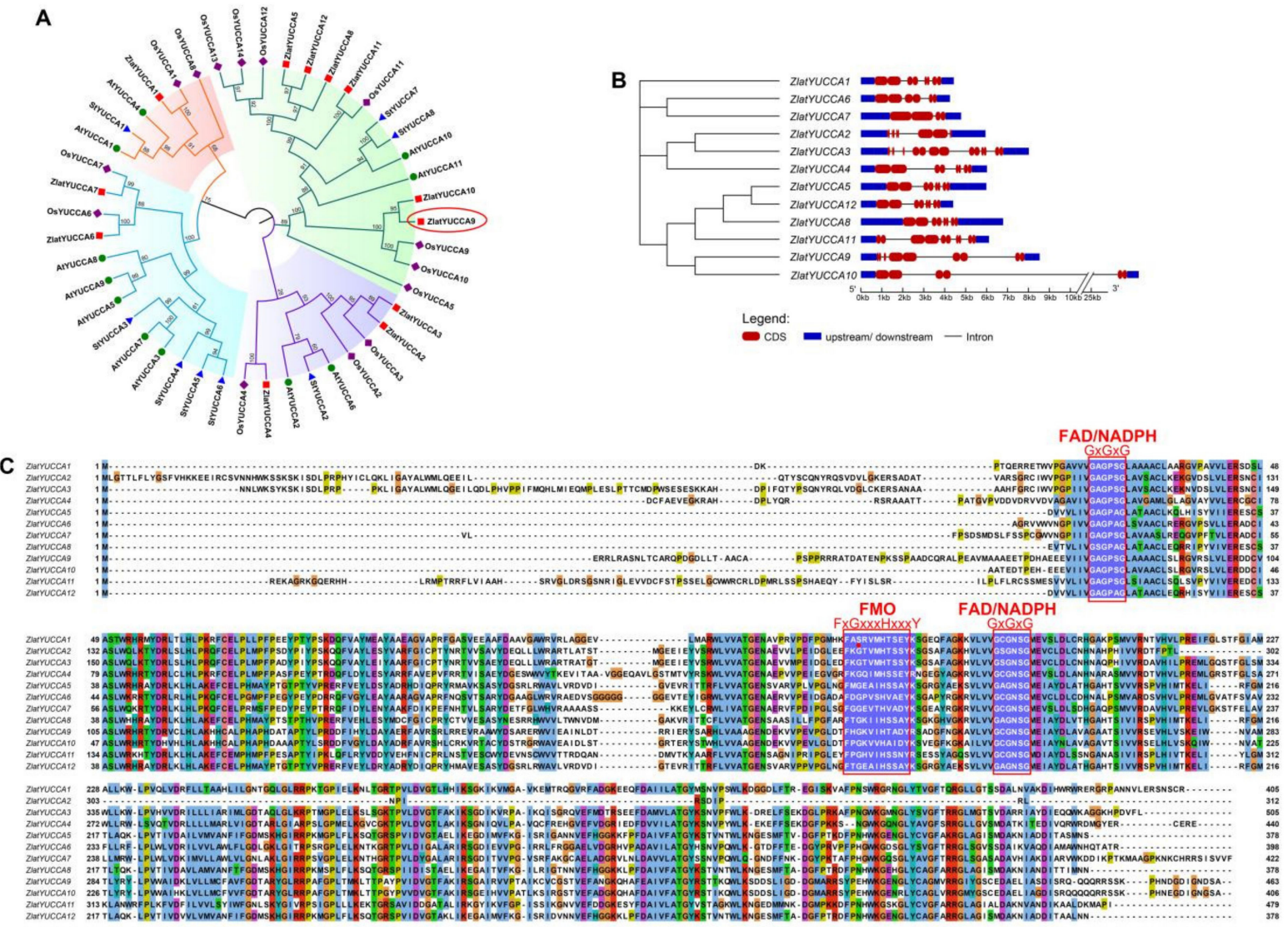

Figure 7. YUCCA gene family analysis. (A) Phylogenetic analysis of the YUCCA protein in Z. latifolia, Arabidopsis, rice and potato. (B) Structural analysis of the YUCCA family. (C) The complete protein sequences of YUCCA family proteins were aligned by ClustalW. The FMO (FxGxxxHxxxy), FAD (GxGxG) and NADPH-binding (GxGxG) domains are marked with a red box. 
2.5.3. Gene Expression of Enzymes Related to IAA Biosynthesis at the Early Stage of Stem-Gall Formation by qRT-PCR

To elucidate the sources of auxin biosynthesis, the expression of genes related to IAA biosynthesis in Z. latifolia and U. esculenta in the initial stage of culm gall formation was analyzed (Figure 8, Table S10). Compared with $-10 \mathrm{~d}$, the expression levels of 1 TAM $\left(G M E 6257 \_g\right.$ ) and 2 IADs (GME621_g and GME6394_g) were significantly decreased, and there was no significant difference in the expression of other enzyme genes during IAA synthesis of $U$. esculenta between two development stages. In Z. latifolia, the change in TAA family genes was not obvious, but particularly interestingly, in the YUCCA family, ZlYUCCA9 (Zlat_10038559) was significantly upregulated in the initial stage of culm gall formation. The expression pattern of other genes involved in IAA biosynthesis pathways is listed in Table S10, and no remarkable expression level difference of these genes was found. The qRT-PCR results were similar to those of RNA-Seq, which showed a consistent expression trend and indicated that the DEGs obtained by RNA-Seq were reliable. These results also implied that the auxin inducing the initial expansion of the culm gall was mainly biosynthesized by the host plant $Z$. Latifolia rather than the fungus $U$. esculenta, and ZlYUCCA9 played a key role in this process.

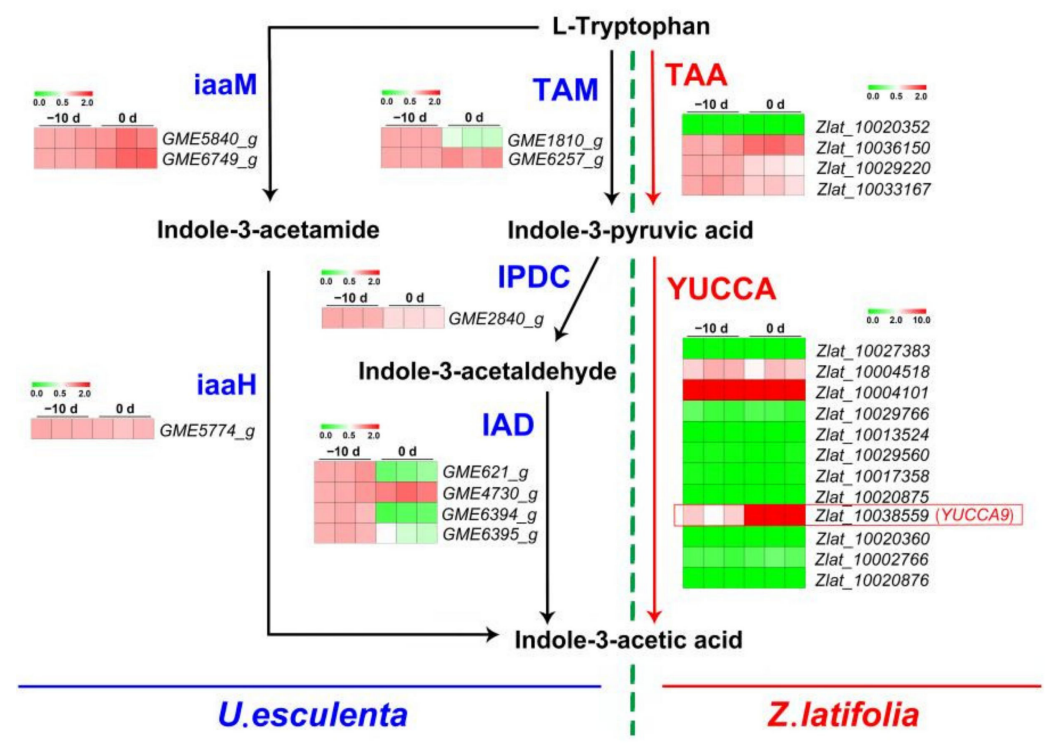

Figure 8. Validation of the RNA-Seq data of key enzymes in the IAA biosynthesis pathway using qRT-PCR at the initial stage of stem-gall formation. Black lines and blue letters denote the IAM pathway and IPyA pathway and the key enzyme in IAA synthesis in U. esculenta. Red lines and letters indicate the IAA synthesis pathway and key enzymes in the host plant Z. latifolia. The relative expression was determined by the $2^{-\Delta \Delta C T}$ method. MeV version 4.9.0 software (Dana-Farber Cancer Institute, Boston, MA, USA) was used for the statistical analysis.

\subsection{Expression Pattern of Cys2-His2 (C2H2) Zinc Finger Proteins of U. esculenta at the Early Stage of Stem-Gall Formation}

To investigate how $U$. esculenta participate in the biological process of gall initiation, differently expressed transcript factors (TFs) of the fungus during gall formation were identified. Interestingly, all 11 differently expressed transcripts annotated as TFs during this stage belong to the $\mathrm{C} 2 \mathrm{H} 2$ family, indicating that these zinc finger proteins may play key roles of Jiaobai gall formation (Figure 9A). Further sequence analysis suggests that all 10 downregulated $\mathrm{C} 2 \mathrm{H} 2$ transcripts have high sequence similiarity and may be produced by alternative splicing from a single gene (Figure S7). Thus, the longest transcript GME5963_g was used as a representative for further analysis. Using BLASTP, 35 C2H2 family genes were obtained from the $U$. esculenta genome (Table S11). The structure of $\mathrm{C} 2 \mathrm{H} 2$ family genes was simple, and the number of introns is no more than 4 , of which 18 genes 
have no introns (Figure S8). Therefore, 35, 46, 45 and $35 \mathrm{C} 2 \mathrm{H} 2$ protein sequences from $U$. esculenta, $U$. maydis, M. oryzae and Saccharomyces cerevisiae were collected for phylogenetic analysis (Figure 9B). In the subgroup containing upregulated GME3058_g, MGG_05133 was involved in the regulation of conidial differentiation [33], MGG_15508 was associated with pathogenicity [33], while um05801 was reported to be upregulated during the biotrophic growth stage [34]. Combining the evidence of hyphae growth in Figure 2, it is reasonable to deduce that GME3058_g may play similar roles during the gall formation as its homologous genes mentioned above. On the other hand, in the subgroup containing downregulated GME5963_g, um02717 was reported to positively regulate the biosynthesis of ustilagic acid, a toxin that confers $U$. maydis biocontrol activity [35]. Whether GME5963_g also regulates ustilagic acid biosynthesis and whether there is a relationship between this secreted cellobiose glycolipid and gall formation of Jiaobai remains to be elucidated. The expression patterns of GME3058 $\_$and GME5963 $\_g$ were further validated by qRT-PCR (Figure 9C).

A
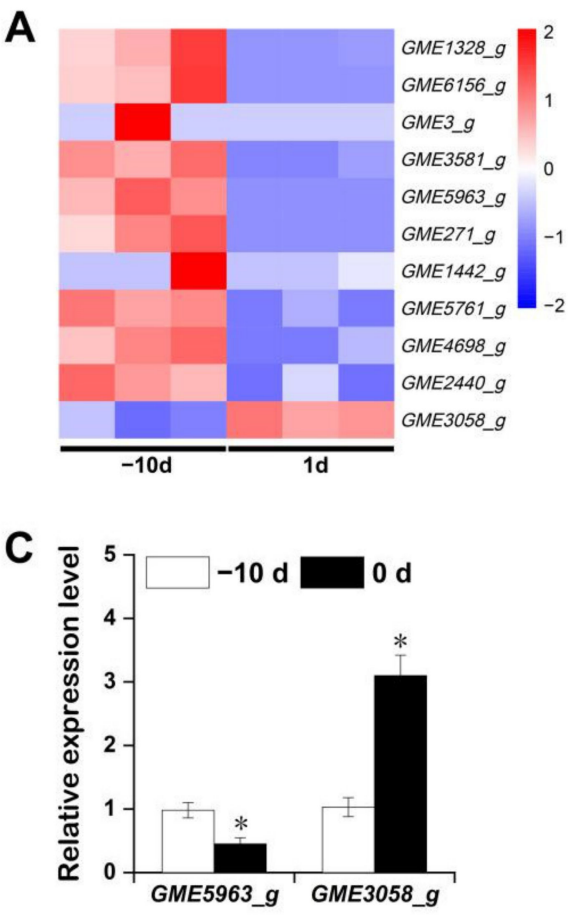

B

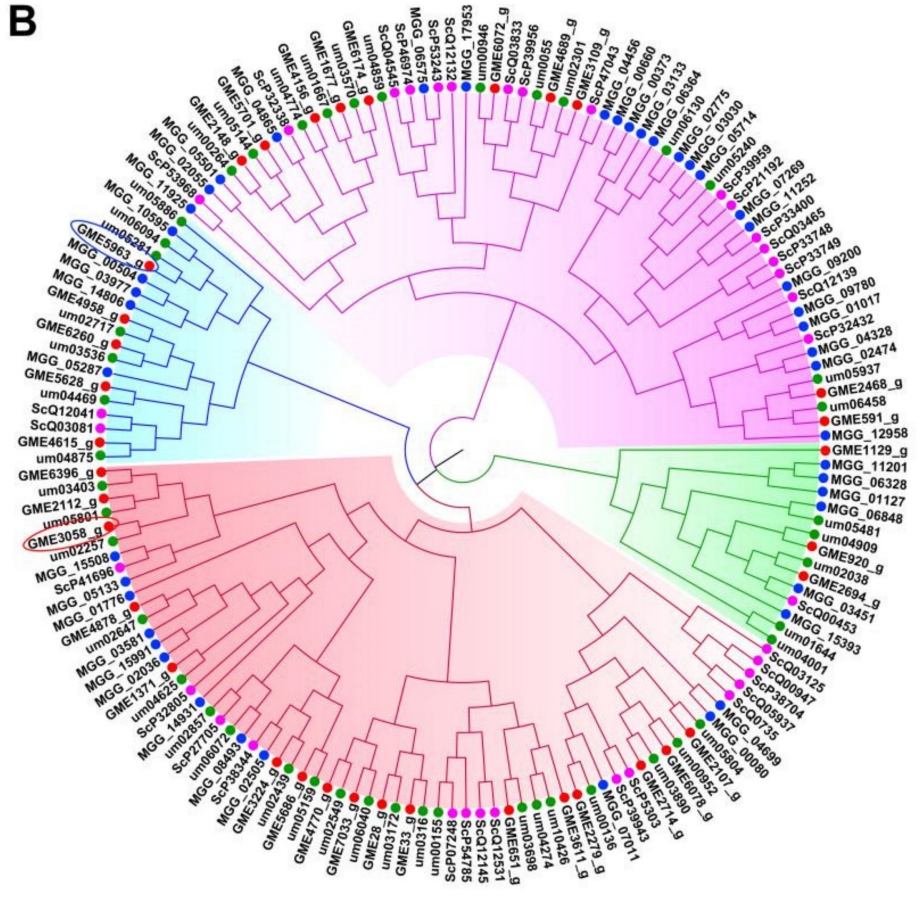

Figure 9. Analysis of $\mathrm{C} 2 \mathrm{H} 2$ zinc finger proteins of $U$. esculenta. (A) Heatmap analysis of $\mathrm{C} 2 \mathrm{H} 2 \mathrm{DEGs}$ in RNA-Seq at the early stage of stem-gall formation. (B) Phylogenetic analysis of the $\mathrm{C} 2 \mathrm{H} 2$ zinc finger proteins in $U$. esculenta (red), U. maydis (green), M. oryzae (blue) and S. cerevisiae (amaranth). red circle: GME3058, blue circle: GME5963_g. (C) Validation of GME3058_g and GME5963_g expression levels in RNA-Seq data using RT-PCR. Asterisks $\left(^{*}\right)$ indicate significant differences $(p<0.05)$ between same gene in the different stage of stem-gall formation.

\section{Discussion}

Jiaobai is a perennial plant with aboveground parts that wither in winter and require several months from sprouting in the spring to the beginning of culm gall expansion. Once a culm gall is formed, it expands rapidly within 1-2 weeks, reaching the size of the commodity period $[8,10]$. Thus, the initial stage of culm gall formation is a key point to understand the interaction mechanism between Z. latifolia and U. esculenta. The interaction between the host and pathogen is also very important in the early stage of disease occurrence when the mycelium began to invade the plant cells, such as in rice and blast fungus and maize and $U$. maydis interactions $[29,36]$. Previous studies have characterized some genes related to stem enlargement in Z. latifolia and $U$. esculenta separately $[10,37,38]$, but the analyses were not sufficiently systematic or comprehensive. RNA-seq has been successfully used to study the patterns of global gene expression in both plants and pathogenic fungi during 
plant-pathogen interactions $[28,29,31]$. It is difficult to detect the expression of fungal genes in the early stage of infection due to the small proportion of pathogens [29]. U. esculenta mycelia were distributed unevenly throughout the culms, and hyphae were abundant in the nodes but rare in the internodes [8]. Our findings showed that the morphology of $U$. esculenta changed dramatically; as the number of hyphae and conidia increased, $U$. esculenta hyphae penetrated the host cells and was mainly distributed in the middle node of the initial stage of the stem gall. Therefore, we selected this tissue for transcriptome sequencing to increase the proportion of pathogens. The results showed that our method could simultaneously detect the expression of a large number of genes in host plants and pathogens during the formation of culm galls in Jiaobai. The proportion of $U$. esculenta genes in the mixed transcriptome of the initial culm gall on day 0 (formation day of Jiaobai) increased compared with that on day -10 (10 days before the expansion of Jiaobai), which was consistent with the increase in U. esculenta cells observed in culm gall tissue sections. Concurrently, some genes specific to Z. latifolia or $U$. esculenta were expressed at $-10 \mathrm{~d}$ and $0 \mathrm{~d}$, respectively. These specific genes involved a variety of metabolic pathways and thus might be closely related to the formation of Jiaobai.

The interaction between host plants and pathogens is closely related to plant diseaseresistance genes and pathogen genes [32,39,40]. In this study, we observed that a total of 368 plant disease-resistance genes and 71 fungal PHI genes showed significant differences in expression levels. These candidate genes may play important roles in the invasion of $U$. esculenta and the ability of $Z$. latifolia to prevent fungal invasion into cells and stimulate culm gall formation. In pathogenic fungi, chitin synthase not only plays an important role in maintaining cell growth but also has a close relationship with pathogenicity [41,42]. In Fusarium oxysporum and $U$. maydis, the mycelia growth and pathogenicity of the chitin synthase-gene-defective mutant were decreased $[36,43]$. In this study, we found similar results: a large number of hyphae extended into the interior of the host tissue, and the expression of the chitin synthase gene GME6969_g in U. esculenta was significantly upregulated in the initial stage of culm gall formation. However, we concurrently noticed that some virulence genes associated with strong pathogenicity, such as GME4426_g, GME6815_g, and GME6967_g, were significantly decreased, and a large number of genes involved in the signaling pathway of plant disease resistance, including leucine replication-rich receptor-like kinases, hormone signaling pathways, plant-pathogen interactions and phenylpropanoid biosynthesis pathways, were clearly changed. These results implied that, on the one hand, U. esculenta hyphae increased and expanded in the host plant simply to maintain proper pathogenicity without causing fatal disease, and on the other hand, the ability of plants to resist fungal infection increased to maintain the long-term interaction and symbiosis between the fungus and the host during the period of stem-gall expansion.

Jiaobai is produced by the interaction of Z. latifolia and $U$. esculenta, and previous studies have shown that plant hormones play an important role in the expansion process of Jiaobai culm gall $[7,9,11]$. Cytokinin and auxin are two important phytohormones widely reported to induce Jiaobai gall formation [9,10]. Wang et al. (2017) and Li et al. (2021) found that several genes involved in cytokinin and IAA biosynthesis were upregulated at gall initiation $[9,10]$. However, in our study, only a few genes involves with cytokinin biosynthesis and signaling pathways were found to be upregulated during gall initiation (Figures 6B and S9). IAA content in the initially expanding gall increased significantly, while contents of cytokinin and GA declined, indicating that IAA played a key role in the initial expansion process of Jiaobai. According to the primer sequences, we found that the key gene of IAA biosynthesis in our study (Zlat_10038559) is the same gene of ZlYUCCA in Wang et al. (2017) [10] and ZlYUC11 in Li et al. (2021) [9], and the expression of this gene was upregulated in all three experiments at the gall initiation stage. The result further confirms the key roles of IAA and Zlat_10038559 during the gall formation of Jiaobai. In addition, Li et al. (2021) reported the IAA level was not regulated between $-5 \mathrm{~d}$ and $5 \mathrm{~d}$ of gall formation [9], and the levels of IAA and $\mathrm{GA}_{3}$ were much higher than those in our study. We noticed that the days associated with gall formation were defined for sampling 
in these studies, however, the exact definition of the day before, at or after gall initiation may be different ( $1 \mathrm{~cm}$ in our study and $5 \mathrm{~cm}$ in Wang et al. (2017) for $0 \mathrm{~d}$ [10], for example). Additionally, as mentioned above, the middle node of the initial stage of the stem gall was sampled for both gene expression and phytohormone assay. Thus, the difference in the sampling time and location may be one of the reasons for the different results among studies. IAA was the first discovered and isolated phytohormone and is the most commonly occurring natural auxin. Interestingly, however, many microorganisms (including bacteria and fungi) have also demonstrated the ability to synthesize IAA, and the role of IAA in plant-microbe interactions has recently received increasing attention $[19,44,45]$. The function of IAA synthesized by microorganisms or plants is quite different in the initial stage of symptoms. According to some reports, certain plant-growth-promoting rhizobacteria and fungi that produce IAA can induce lateral root formation and root hair development $[15,16,46,47]$. Phytopathogenic bacteria such as Agrobacterium tumefaciens and Pseudomonas syringae is synthesize IAA, which is used as a virulence factor to cause tumors and galls [44,46-48]. Other reports have suggested that most IAA is contributed by the host plant during the initial critical interaction between tobacco (Nicotiana tabacum) and P. solanaceraum [15,16]; Reineke et al. (2008) also found that auxin synthase-gene-deletion mutants of smut fungus U. maydis-inoculated maize did not affect tumor formation, and considered that fungal IAA production provides a critical contribution to IAA levels in the infected tissue [18]. However, this phenomenon is apparently not important for triggering host tumor formation. Li et al. (2021) found that several genes in IAA biosynthesis and signaling pathways were upregulated during gall formation [9]. To identify if the IAA was produced by U. esculenta or its host plant at the initiation stage of gall enlargement, we analyzed the expression of genes encoding key enzymes during IAA synthesis in the two species. We observed that there were no significant differences or even a downregulation of the expression levels of IAA synthesis-related genes of $U$. esculenta at the time of calm gall formation. YUCCA proteins convert indole-3-pyruvate (IPyA) into indole-3-acetic acid (IAA) and are essential for auxin production. They play important roles in plant growth and development. The expression levels of the YUCCAs are closely related to the content of IAA, and overexpression of YUCCA genes results in elevated auxin levels and auxin-overproduction phenotypes in Arabidopsis, rice, potato and cucumber [25-27,49]. In addition, Lin et al. [50] found that the expression of YUCCA increased significantly during potato tuber formation. In this study, 12 YUCCA genes were identified, and further phylogenetic analysis and expression pattern analysis showed that the trend of ZlYUCCA9 expression and auxin content was consistent during the initial formation of fleshy stems. It was speculated that the auxin triggering calm gall initiation is mainly synthesized by the host plant and not by smut fungi.

There is no doubt that the gall formation of Jiaobai is a result of the interaction of U. esculenta and Z. latifolia. Therefore, if the IAA inducing gall enlargement initiation is dominantly synthesized by $Z$. latifolia, the role of $U$. esculenta in the gall initiation remains unclear. $\mathrm{C} 2 \mathrm{H} 2$ zinc finger protein is one of the largest and most important transcript factor families in fungi and was reported to be associated with a variety of biological process including fungal development, pathogenicity, conidiation, biotrophic growth and so on [33-35]. In our study, several $\mathrm{C} 2 \mathrm{H} 2$ genes, closely homologous with these reported genes, were differently expressed during the early gall formation stage. At the same time, significant hyphae growth and invasion into the host cells were also found, indicating similar biological events occurred when the gall started to enlarge. The precondition of fungus triggering gall enlargement is that the fungi should widely distribute into the plant tissue. After that, $U$. esculenta could affect the tissue growth more efficiently by synthesizing phytohormones and other bioactive substances $[7,9,17]$. To explore whether crosstalk exists between $U$. esculenta and Z. latifolia at the early stage of gall formation, the promoter sequence of ZlYUCCA9 (the $-2000 \mathrm{bp}$ upstream from initiation codon) and the protein sequence of GME5963_g were co-analyzed with the JASPAR database (https:/ /jaspar.genereg.net/, accessed on 5 October 2021), and several C2H2 zinc finger 
protein binding motifs were identified in this region (Table S12). Thus, we could not exclude the possibility of plant-fungus crosstalk in the plant's auxin biosynthesis pathway (Figure 10).

Taken together, our results indicated that $U$. esculenta grew quickly and invaded hostplant cells at the initial stage of stem-gall formation, accompanied by a large number of gene expression changes in both Z. latifolia and $U$. esculenta. Mixed transcriptome analysis helps to elucidate the interactions between host-plant defense and pathogen attack. Auxin plays a key regulatory role in triggering the stem swelling of Jiaobai, and it may be mainly synthesized by Z. latifolia, in which ZlYUCCA9 plays a critical role. GME3058_g and GME5963_g are two important candidate $\mathrm{C} 2 \mathrm{H} 2$ zinc finger proteins conducting $U$. esculenta growth and infection in the initial stage of stem-gall formation.

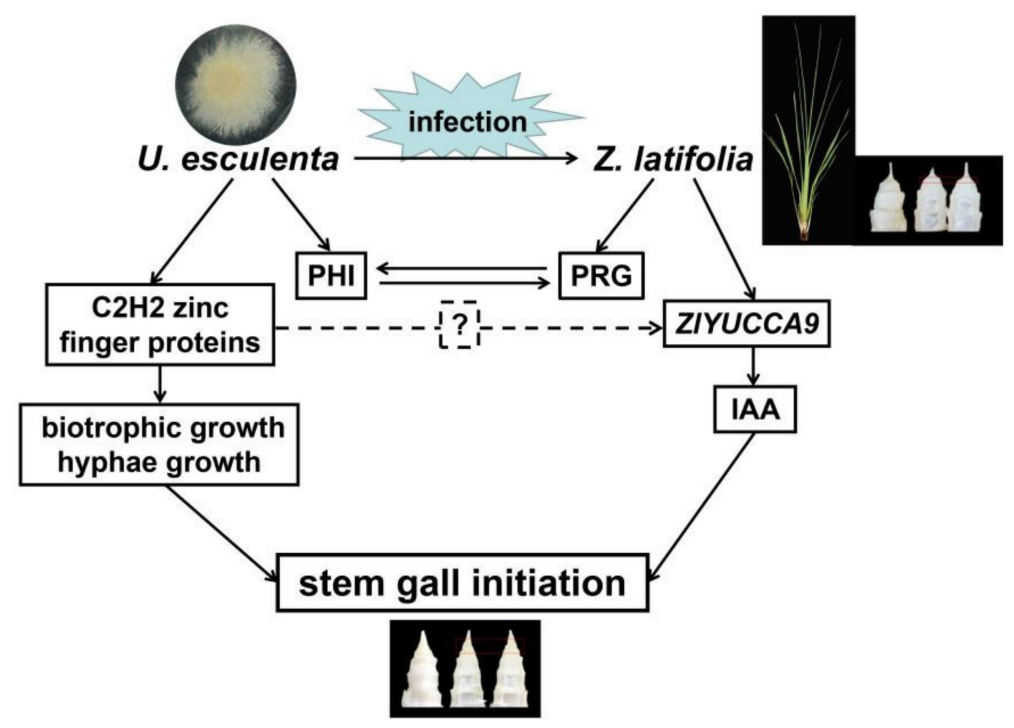

Figure 10. A proposed model of the interaction mechanism between Z. latifolia and U. esculenta for stem-gall induction deduced from mixed transcriptome analysis. At this stage, the hyphae of U. esculenta extend fast and invade into stem apex cells of the host, which may be promoted by the $\mathrm{C} 2 \mathrm{H} 2$ zinc finger proteins. The wide distribution of hyphae into the host tissue would facilitate triggering gall enlargement after initiation stage. Fungal pathogen-host interaction genes (PHI) and plant resistant genes (PRG) are reprogrammed to maintain the unique balance between the parasite and the host. IAA stimulating Jiaobao stem-gall initiation is mainly synthesized by Z. latifolia, and ZlYUCCA9 may play a key role in this process. $\mathrm{C} 2 \mathrm{H} 2$ zinc finger proteins of $U$. esculenta may also participate into the IAA synthesis of Z. latifolia.

\section{Materials and Methods}

\subsection{Plant Material and Sample Collection}

Z. latifolia plants were grown in plastic pots (diameter $53.5 \mathrm{~cm}$ and height $37.5 \mathrm{~cm}$ ) filled with garden soil under natural conditions at the Aquatic Vegetables Experimental Station of Yangzhou University $\left(119^{\circ} 42^{\prime}\right.$ E, $32^{\circ} 24^{\prime}$ N), Yangzhou, Jiangsu Province, China. Seedlings with uniform size at the 4-leaf stage were planted. According to our previous work [51], the stem gall should initiate enlargement about $120 \mathrm{~d}$ after planting under certain experimental conditions. Thus, samples were collected at 110 days (noted as $-10 \mathrm{~d}$ ) and 120 days (noted as $0 \mathrm{~d}$ ) after planting. To increase the proportion of $U$. esculenta in the culm gall, $0.5 \mathrm{~cm}$ of the upper part of the gall was removed, while the nodes and the internodes adjacent to them (approximately $0.2 \mathrm{~cm}$ ) were selected as materials for further analysis (Figure 1C,D). Typical characteristics of the junctions of the leaf sheath and leaves, height, width and color of leaves and stem apex morphology were used to further confirm the development stage of the culm gall. All samples with three biological repeats (approximately 15-20 stems of different plants were collected per replication) were frozen in liquid nitrogen immediately and stored at $-80^{\circ} \mathrm{C}$ for further experiments. 


\subsection{Distribution of Hyphae in Z. latifolia}

The distribution of $U$. esculenta hyphae in Z. latifolia was observed using paraffin sectioning and scanning electron microscopy (SEM). According to the size of plant tissue, the whole stem apical tissues of $-10 \mathrm{~d}$ and five tissue parts (from up to bottom (1-5): stem apex, first node, second node, internode, bottom) of the initial swollen stem $(0 \mathrm{~d})$ were used (Figure $1 \mathrm{~A}(\mathrm{a}, \mathrm{c})$ ). The paraffin sections were generated as described by Zhang et al. [12], and the morphology of $U$. esculenta in the plant was observed with an Olympus BX-51 microscope (Olympus Optical, Japan). For SEM measurements, the samples were prepared as previously described [52] with slight modifications. The samples were fixed with $2.5 \%$ glutaraldehyde and kept overnight at $4{ }^{\circ} \mathrm{C}$. After washing with $0.1 \mathrm{~mol} / \mathrm{L} \mathrm{PBS}$ several times and once with deionized water, they were dehydrated using a graded series of ethanol $(30 \%, 50 \%, 70 \%, 80 \%, 90 \%, 95 \%, 100 \%)$ and dried in an automated critical point dryer (Leica EM-CPD300, Vienna, Austria). Then, the samples were mounted on aluminum stubs by placing them on double-sided adhesive tape and sputtered with a thin layer of gold using a vacuum sputter coater (Leica-EM SCD500, Germany). SEM images were recorded on a Gemini SEM 300 (Zeiss, German) running at $5.0 \mathrm{kV}$.

\subsection{RNA Isolation, $m R N A$-Seq Library Preparation and Sequencing}

Total RNA was extracted from Z. latifolia using RNAiso Plus (total RNA-extraction reagent) (Takara, Japan). The concentration of total RNA, Rin value, 28S/18S and fragment size were detected using an Agilent 2100 Bioanalyzer (Agilent RNA 6000 nano Kit), and the RNA purity of the plant and fungal samples was measured with a NanoDrop ${ }^{\mathrm{TM}}$. The mRNA was enriched with magnetic beads bearing oligos (dT), double-stranded cDNA was synthesized using the NEBNext ${ }^{\circledR}$ Ultra $^{\mathrm{TM}}$ II RNA Library Prep Kit for Illumina, and cDNA was purified with an Agencourt AMPure XP Kit (Beckman, Indianapolis, IN, USA). The constructed library was tested using an Agilent 2100 Bioanalyzer (Agilent, Santa Clara, CA, USA) and a One Step Plus real-time PCR system (ABI, Vernon, CA, USA) and then sequenced using the DNBSEQ ${ }^{\mathrm{TM}}$ platform (BGI-Shenzen, China).

\subsection{Preprocessing of mRNA Sequence Data}

The raw RNA-Seq reads were preprocessed with SOAPnuke v1.4.0 [53] (https:// github.com/BGI-flexlab/SOAPnuke, accessed on 5 October 2021) to remove reads with adapter contamination, an $\mathrm{N}$ base ratio greater than $5 \%$, and low-quality reads. The clean reads were first mapped to the Z. latifolia genome (INSDC:ASSH00000000.1) and the U. esculenta genome (INSDC: JAAKGJ010000000) [51] using HISAT v2.1.0 (http:// www.ccb.jhu.Edu/software/hisat, accessed on 5 October 2021) [54]. After that the Bowtie2 v2.2.5 (http://bowtie-bio.sourceforge.net/bowtie2/index.shtml, accessed on 5 October 2021) was applied to align the clean reads to the gene set [55], then the expression levels of genes and transcripts were quantified using RSEM v1.2.12 (http:/ / deweylab.biostat. wisc.edu/rsem/rsem-calculate-expression.html, accessed on 5 October 2021) [56] and estimated with fragments per kilobase of exon per million mapped reads (FPKM) values. The significantly different DEGs between the two groups were analyzed by DEGseq, where the fold change represented the ratio of the expression level between the two samples, and a fold change $\geq 2$ and $p$-value $\leq 0.001$ were used as filtering criteria [57].

\subsection{Functional Annotation of DEGs}

Functional annotation of DEGs was accomplished by aligning genes with the NR, Swiss-PROt, GO, COG, KOG and KEGG databases using Blast2GO (http:/ / www.blast2go. org, accessed on 5 October 2021). Plant disease-resistance genes and potential virulencerelated proteins were identified by searching against the Plant Resistance Gene Database (PRGdb) and Pathogen-Host Interaction database (PHI-base) using DIAMOND v0.8.31 by BLASTP according to the query coverage and identity with E-values $\leq 1 \times 10^{-5}$. 


\subsection{ESI-HPLC-MS/MS Assay of Endogenous Hormones}

The endogenous hormones IAA, ABA, JA, $\mathrm{SA}, \mathrm{GA}_{1}, \mathrm{GA}_{3}$, and zeatin were analyzed by HPLC-MS/MS according to the method by Pan et al. (2010) [58]. The 7 analytes were separated using a Poroshell 120 SB-C18 column $(2.1 \times 150 \mathrm{~mm}, 2.7 \mu \mathrm{m})$ with the mobile phase containing water and methanol in gradient elution mode on an Agilent 1290 highperformance liquid chromatograph (Agilent, Santa Clara, CA, USA). The flow rate was $0.3 \mathrm{~mL} / \mathrm{min}$, and the column temperature was $30^{\circ} \mathrm{C}$. Then, a quantitative analysis was performed in multiple-reaction monitoring (MRM) mode with electrospray ionization (ESI) on an AB SCIEX QTRAP 6500+LC-MS/MS system (AB, Fairfield, OH, USA).

\subsection{Genome-Wide Identification of the IAA Synthesis Genes and C2H2 Zinc Finger Proteins in U. esculenta and Z. latifolia}

The protein sequences of TAM, IPDC and IAD in the IPyA pathway, IaaM and iaaH in the IAM pathway, nitrilase in the indole-3-acetonitrile (IAN) pathway, and $\mathrm{C} 2 \mathrm{H} 2$ zinc finger proteins of $U$. maydis [18,34], Neurospora crassa [20], and Fusarium proliferatum [21], and TAA and YUCCA in the TAA/YUCCA pathway and IAM pathway of Arabidopsis $[23,24,26]$ were used as query sequences to search for the corresponding gene family members in the $U$. esculenta and Z. latifolia genomes by BLASTP, and the threshold was set to $\mathrm{E}<10^{-5}$. The protein sequences of the YUCCAs in Z. latifolia were aligned with Arabidopsis [24], potato [25], and rice [26] using MAFFT [59] and the protein sequences of the $\mathrm{C} 2 \mathrm{H} 2$ zinc finger proteins in U. esculenta were aligned with M. oryzae [33], U. maydis [34,35] and S. cerevisiae by ClustalW, using default parameters. The phylogenetic analysis was constructed using FastTree [60] with default parameters and displayed using iTol [61]. Furthermore, according to the genomic DNA and CD sequences of UeC2H2s and ZlYUCCAs, the gene structure was analyzed using the online tool GSDS2.0 (http:/ /gsds.cbi.pku.edu.cn/, accessed on 5 October 2021).

\subsection{Confirmation of DEGs by $q R T-P C R$}

Several genes associated with the IAA synthesis and two $\mathrm{C} 2 \mathrm{H} 2$ zinc finger protein genes in plants and fungi were selected and confirmed by qRT-PCR. Primers for qRT-PCR were designed using Primer Premier 5.0 and are listed in Table S13 in the Supplementary Materials. PCR amplifications were performed using the Bio-Rad CFX Connect ${ }^{\mathrm{TM}}$ RealTime system (BIO-RAD, Hercules, CA, USA) with a final volume of $20 \mu \mathrm{L}$ containing $10 \mu \mathrm{L}(2 \times)$ iTaq $^{\mathrm{TM}}$ Universal SYBR $^{\circledR}$ Green Supermix (BIO-RAD), $1 \mu \mathrm{L}$ of cDNA, $0.5 \mu \mathrm{L}$ of forward primer $(10 \mu \mathrm{M}), 0.5 \mu \mathrm{L}$ of reverse primer $(10 \mu \mathrm{M})$, and $8 \mu \mathrm{L}$ of sterile water. For each gene, three technical replicates were evaluated. The amplification procedure was as follows: denaturation at $95^{\circ} \mathrm{C}$ for $3 \mathrm{~min}$, followed by 39 cycles of $95^{\circ} \mathrm{C}$ for $10 \mathrm{~s}, 56^{\circ} \mathrm{C}$ for $30 \mathrm{~s}$, melt curve 60.0 to $95^{\circ} \mathrm{C}$, and increment $0.5^{\circ} \mathrm{C}$ for $0.05 \mathrm{~s}$. The transcript level of each gene was normalized against the expression levels of $Z$. latifolia $18 \mathrm{~S}$ rRNA and U. esculenta actin. The $2^{-\Delta \Delta C T}$ method was used to calculate the relative gene expression levels.

Supplementary Materials: The following are available online at: https:/ / www.mdpi.com/article/ $10.3390 /$ ijms222212258/s1.

Author Contributions: Z.-P.Z., J.-Z.J. and M.-M.M. conceived, designed and supervised the experiments; S.-X.S. and Y.-C.L. performed the experiments and analyzed the data; X.-R.Z., Y.-F.J. and L.-T.S. contributed reagents/materials/analysis tools; Z.-P.Z. wrote and revised the manuscript. All authors have read and agreed to the published version of the manuscript.

Funding: This work was supported by the Jiangsu Agriculture Science and Technology Innovation Fund (CX(20)3104, CX(19)3034), the open funds of the Jiangsu Key Laboratory of Crop Genomics and Molecular Breeding (NO. ML202006), Project of Jiangsu Province Science and Technology (BE2017380) and the 58th batch of the China Postdoctoral Science Foundation (2015M580478).

Conflicts of Interest: The authors declare no conflict of interest. 


\section{References}

1. Guo, H.B.; Li, S.M.; Peng, J.; Ke, W.D. Zizania latifolia turcz. cultivated in China. Genet. Resour. Crop Evol. 2007, $54,1211-1217$. [CrossRef]

2. Yang, H.C.; Leu, L.S. Formation and histopathology of galls induced by Ustilago esculenta in Zizania latifolia. Phytopathology 1978, 68, 1572-1576. [CrossRef]

3. Jose, R.C.; Bengyella, L.; Handique, P.J.; Talukdar, N.C. Cellular and proteomic events associated with the localized formation of smut-gall during Zizania latifolia-Ustilago esculenta interaction. Microb. Pathog. 2018, 126, 79-84. [CrossRef]

4. Brefort, T.; Doehlemann, G.; Mendoza-Mendoza, A.; Reissmann, S.; Djamei, A.; Kahmann, R. Ustilago maydis as a pathogen. Annu. Rev. Phytopathol. 2009, 47, 423-445. [CrossRef]

5. Zuo, W.L.; Ökmen, B.; DePotter, J.R.L.; Ebert, M.K.; Redkar, A.; Villamil, J.C.M.; Doehlemann, G. Molecular interactions between smut fungi and their host plants. Annu. Rev. Phytopathol. 2019, 57, 411-430. [CrossRef]

6. Wang, M.C.; Zhao, S.W.; Zhu, P.L.; Nie, C.Z.P.; Ma, S.P.; Wang, N.F.; Du, X.F.; Zhou, Y.B. Purification, characterization and immunomodulatory activity of water extractable polysaccharides from the swollen culms of Zizania latifolia. Int. J. Biol. Macromol. 2018, 107, 882-890. [CrossRef] [PubMed]

7. Wang, Z.H.; Yan, N.; Luo, X.; Guo, S.; Xue, S.Q.; Liu, J.Q.; Zhang, J.Z.; Guo, D.P. Gene expression in the smut fungus Ustilago esculenta governs swollen gall metamorphosis in Zizania latifolia. Microb. Pathog. 2020, 143, 104107. [CrossRef] [PubMed]

8. Zhang, J.Z.; Chu, F.Q.; Guo, D.P.; Hyde, D.K.; Xie, G.L. Cytology and ultrastructure of interactions between Ustilago esculenta and Zizania latifolia. Mycol. Prog. 2012, 11, 499-508. [CrossRef]

9. Li, J.; Lu, Z.Y.; Yang, Y.; Hou, J.F.; Yuan, L.Y.; Chen, G.H.; Wang, C.G.; Jia, S.K.; Feng, X.M.; Zhu, S.D. Transcriptome analysis reveals the symbiotic mechanism of Ustilago esculenta-Induced gall formation of Zizania latifolia. Mol. Plant-Microbe Interact. 2021, 34, 168-185. [CrossRef]

10. Wang, Z.D.; Yan, N.; Wang, Z.H.; Zhang, X.H.; Zhang, J.Z.; Xue, H.M.; Wang, L.X.; Zhan, Q.; Xu, Y.P.; Guo, D.P. RNA-seq analysis provides insight into reprogramming of culm development in Zizania latifolia induced by Ustilago esculenta. Plant Mol. Biol. 2017, 95, 533-547. [CrossRef]

11. Lambrecht, M.; Okon, Y.; Broek, A.V.; Vanderleyden, J. Indole-3-acetic acid: A reciprocal signalling molecule in bacteria-plant interactions. Trends Microbiol. 2000, 8, 298-300. [CrossRef]

12. Jain, M.; Khurana, J.P. Transcript profiling reveals diverse roles of auxin-responsive genes during reproductive development and abiotic stress in rice. FEBS J. 2009, 276, 3148-3162. [CrossRef] [PubMed]

13. Sauer, M.; Robert, S.; KleineVehn, J. Auxin: Simply complicated. J. Exp. Bot. 2013, 64, 2565-2577. [CrossRef]

14. Vanneste, S.; Friml, J. Auxin: A trigger for change in plant development. Cell 2009, 136, 1005-1016. [CrossRef]

15. Kazan, K.; Manners, J.M. Linking development to defense: Auxin in plant-pathogen interactions. Trends Plant Sci. 2009, 14, 373-382. [CrossRef]

16. Yamada, T. The role of Auxin in plant-disease development. Annu. Rev. Phytopathol. 1993, 31, 253-273. [CrossRef] [PubMed]

17. Chung, K.R.; Tzeng, D.D. Biosynthesis of indole-3-acetic acid by the gall-inducing fungus Ustilago esculenta. J. Biol. Sci. 2004, 4, 744-750. [CrossRef]

18. Reineke, G.; Heinze, B.; Schirawski, J.; Buettner, H.; Kahmann, R.; Basse, C.W. Indole-3-acetic acid (IAA) biosynthesis in the smut fungus Ustilago maydis and its relevance for increased IAA levels in infected tissue and host tumour formation. Mol. Plant Pathol. 2008, 9, 339-355. [CrossRef]

19. Tivendale, N.D.; Ross, J.J.; Cohen, J.D. The shifting paradigms of auxin biosynthesis. Trends Plant Sci. 2014, 19, 44-51. [CrossRef] [PubMed]

20. Puspendu, S.; Frank, K.; Borkovich, K.A. Characterization of indole-3-pyruvic acid pathway-mediated biosynthesis of auxin in Neurospora crassa. PLoS ONE 2018, 13, 0192293. [CrossRef]

21. Tsavkelova, E.; Oeser, B.; Oren-Young, L.; Israeli, M.; Sasson, Y.; Tudzynski, B.; Sharon, A. Identification and functional characterization of indole-3-acetamide-mediated IAA biosynthesis in plant-associated Fusarium species. Fungal Genet. Biol. 2012, 49, 48-57. [CrossRef] [PubMed]

22. Won, C.; Shen, X.L.; Mashiguchi, K.; Zheng, Z.Y.; Dai, X.H.; Cheng, Y.F.; Kasahara, H.; Kamiya, Y.; Chory, J.; Zhao, Y.D. Conversion of tryptophan to indole-3-acetic acid by tryptophan aminotransferases of Arabidopsis and YUCCAs in Arabidopsis. Proc. Natl. Acad. Sci. USA 2011, 108, 18518-18523. [CrossRef] [PubMed]

23. Gao, Y.B.; Dai, X.H.; Aoi, Y.K.; Takebayashi, Y.; Yang, L.P.; Guo, X.R.; Zeng, Q.W.; Yu, H.; Kasahara, H.; Zhao, Y.D. Two homologous INDOLE-3-ACETAMIDE (IAM) HYDROLASE genes are required for the auxin effects of IAM in Arabidopsis. J. Genet. Genom. 2020, 47, 157-165. [CrossRef]

24. Kendrew, S.G. YUCCA: A flavin monooxygenase in auxin biosynthesis. Trends Biochem. Sci. 2001, 26, 218. [CrossRef]

25. Kim, J.L.; Baek, D.; Park, H.C.; Chun, H.J.; Oh, D.H.; Lee, M.K.; Cha, J.Y.; Kim, W.Y.; Kim, M.C.; Chung, W.S.; et al. Overexpression of Arabidopsis YUCCA6 in potato results in high-auxin developmental phenotypes and enhanced resistance to water deficit. Mol. Plant 2013, 6, 337-349. [CrossRef]

26. Yamamoto, Y.; Kamiya, N.; Morinaka, Y.; Matsuoka, M.; Sazuka, T. Auxin biosynthesis by the YUCCA genes in rice. Plant Physiol. 2007, 143, 1362-1371. [CrossRef]

27. Zhao, Y.; Christensen, S.K.; Fankhauser, C.; Cashman, J.R.; Cohen, J.D.; Weigel, D.; Chory, J. A role for flavin monooxygenase-like enzymes in auxin biosynthesis. Science 2001, 291, 306-309. [CrossRef] 
28. Doehlemann, G.; Wahl, R.; Horst, R.J.; Voll, L.M.; Usadel, B.; Poree, F.; Stitt, M.; Pons-Kühnemann, J.; Sonnewald, U.; Kahmann, R.; et al. Reprogramming a maize plant: Transcriptional and metabolic changes induced by the fungal biotroph Ustilago maydis. Plant J. 2008, 56, 181-195. [CrossRef]

29. Kawahara, Y.; Oono, Y.; Kanamori, H.; Matsumoto, T.; Itoh, T.; Minami, E. Simultaneous RNA-Seq analysis of a mixed transcriptome of rice and blast fungus interaction. PLOS ONE 2012, 7, e49423. [CrossRef]

30. Teixeira, P.J.; Thomazella, D.P.; Reis, O.; Prado, P.F.; Rio, M.C.; Fiorin, G.L.; José, J.; Costa, G.G.; Negri, V.A.; Mondego, J.M.C.; et al. High-resolution transcript profiling of the atypical biotrophic interaction between theobroma cacao and the fungal pathogen moniliophthora perniciosa. Plant Cell 2014, 26, 4245-4269. [CrossRef]

31. Camilios-Neto, D.; Bonato, P.; Wassem, R.; Tadra-Sfeir, M.Z.; Brusamarello-Santos, L.C.; Valdameri, G.; Donatti, L.; Faoro, H.; Weiss, V.A.; Chubatsu, L.S.; et al. Dual RNA-seq transcriptional analysis of wheat roots colonized by Azospirillum brasilense reveals up-regulation of nutrient acquisition and cell cycle genes. BMC Genom. 2014, 15, 378. [CrossRef]

32. Wu, J.; Zhao, Q.; Yang, Q.Y.; Liu, H.; Li, Q.Y.; Yi, X.Q.; Cheng, Y.; Guo, L.; Fan, C.C.; Zhou, Y.M. Comparative transcriptomic analysis uncovers the complex genetic network for resistance to sclerotinia sclerotiorum in Brassica napus. Sci. Rep. 2016, 6, 19007. [CrossRef]

33. Cao, H.; Huang, P.; Zhang, L.L.; Shi, Y.K.; Sun, D.D.; Yan, Y.X.; Liu, X.H.; Dong, B.; Chen, G.Q.; Snyder, J.H.; et al. Characterization of $47 \mathrm{Cys}_{2}-\mathrm{His}_{2}$ zinc finger proteins required for the development and pathogenicity of the rice blast fungus Magnaporthe oryzae. New Phytol. 2016, 211, 1035-1051. [CrossRef] [PubMed]

34. Zheng, Y.; Kief, J.; Auffarth, K.; Farfsing, J.W.; Mahlert, M.; Nieto, F.; Basse, C.W. The Ustilago maydis Cys(2)His(2)-type zinc finger transcription factor Mzr1 regulates fungal gene expression during the biotrophic growth stage. Mol. Microbiol. 2008, 68, 1450-1470. [CrossRef] [PubMed]

35. Teichmann, B.; Liu, L.; Schink, K.O.; Bölker, M. Activation of the Ustilagic acid biosynthesis gene cluster in Ustilago maydis by the $\mathrm{C}_{2} \mathrm{H}_{2}$ zinc finger transcription factor rua1. Appl. Environ. Microbiol. 2010, 76, 2633-2640. [CrossRef]

36. Weber, I.; Assmann, D.; Thines, E.; Steinberg, G. Polar localizing class V myosin chitin synthases are essential during early plant infection in the plant pathogenic fungus Ustilago maydis. Plant Cell 2005, 18, 225-242. [CrossRef] [PubMed]

37. Nakajima, M.; Yamashita, T.; Takahashi, M.; Nakano, Y.; Takeda, T. Identification, cloning, and characterization of $\beta$-glucosidase from Ustilago esculenta. Appl. Microbiol. Biotechnol. 2012, 93, 1989-1998. [CrossRef]

38. Liang, S.W.; Huang, Y.H.; Chiu, J.Y.; Tseng, H.W.; Huang, J.H.; Shen, W.C. The smut fungus Ustilago esculenta has a bipolar mating system with three idiomorphs larger than $500 \mathrm{~kb}$. Fungal Genet. Biol. 2019, 126, 61-74. [CrossRef]

39. Scofield, S.R.; Tobias, C.M.; Rathjen, J.P.; Chang, J.H.; Lavelle, D.T.; Michelmore, R.W.; Staskawicz, B.J. Molecular basis of gene-for-gene specificity in bacterial speck disease of tomato. Science 1996, 274, 2063-2065. [CrossRef]

40. Kourelis, J.; Van Der Hoorn, R.A.L. Defended to the nines: 25 Years of resistance gene cloning identifies nine mechanisms for R protein function. Plant Cell 2018, 30, 285-299. [CrossRef]

41. Roncero, C. The genetic complexity of chitin synthesis in fungi. Curr. Genet. 2002, 41, 367-378. [CrossRef] [PubMed]

42. Lee, J.I.; Choi, J.H.; Park, B.C.; Park, Y.H.; Lee, M.Y.; Park, H.M.; Maeng, P.J. Differential expression of the chitin synthase genes of Aspergillus nidulans, chs $A$, chs $B$, and chs $C$, in response to developmental status and environmental factors. Fungal Genet. Biol. 2004, 41, 635-646. [CrossRef] [PubMed]

43. Martín-Udíroz, M.; Madrid, M.P.; Roncero, M.I.G. Role of chitin synthase genes in Fusarium oxysporum. Microbiology 2004, 150, 3175-3187. [CrossRef] [PubMed]

44. Spaepen, S.; Vanderleyden, J. Auxin and plant-microbe interactions. Cold Spring Harb. Perspect. Biol. 2011, 3, a001438. [CrossRef]

45. Fu, J.; Wang, S.P. Insights into auxin signaling in plant-pathogen interactions. Front. Plant Sci. 2011, 2, 74. [CrossRef]

46. Nassar, A.H.; El-Tarabily, K.A.; Sivasithamparam, K. Promotion of plant growth by an auxin-producing isolate of the yeast Williopsis saturnus endophytic in maize (Zea mays L.) roots. Biol. Fertil. Soils 2005, 42, 97-108. [CrossRef]

47. Glickmann, E.; Gardan, L.; Jacquet, S.; Hussain, S.; Elasri, M.; Petit, A.; Dessaux, Y. Auxin production is a common feature of most pathovars of Pseudomonas syringae. Mol. Plant-Microbe Interact. 1998, 11, 156-162. [CrossRef]

48. Mole, B.M.; Baltrus, D.; Dangl, J.L.; Grant, S.R. Global virulence regulation networks in phytopathogenic bacteria. Trends Microbiol. 2007, 15, 363-371. [CrossRef]

49. Yan, S.S.; Che, G.; Ding, L.; Chen, Z.J.; Liu, X.F.; Wang, H.Y.; Zhao, W.S.; Ning, K.; Zhao, J.Y.; Tesfamichael, K.; et al. Different cucumber CsYUC genes regulate response to abiotic stresses and flower development. Sci. Rep. 2016, 6, 20760. [CrossRef] [PubMed]

50. Lin, T.; Sharma, P.; Gonzalez, D.H.; Viola, I.L.; Hannapel, D.J. The impact of the long-distance transport of a BEL1-like messenger RNA on development. Plant Physiol. 2013, 161, 760-772. [CrossRef]

51. Zhang, Z.P.; Xu, S.X.; Kong, M.Q.; Dai, H.B.; Liu, Y.C.; Miao, M.M. Isolation, identification and artificial inoculation of Ustilago esculenta on Zizania latifolia. Hortic. Plant J. 2020, 7, 347-358. [CrossRef]

52. Waikhom, S.D.; Louis, B.; Roy, P.; Singh, W.M.; Bharwaj, P.K.; Talukdar, N.C. Scanning electron microscopy of pollen structure throws light on resolving bambusa-dendrocalamus complex: Bamboo flowering evidence. Plant Syst. Evol. 2014, 300, 1261-1268. [CrossRef]

53. Cock, P.J.A.; Fields, C.J.; Goto, N.; Heuer, M.L.; Rice, P.M. The Sanger FASTQ file format for sequences with quality scores, and the Solexa/Illumina FASTQ variants. Nucleic Acids Res. 2010, 38, 1767-1771. [CrossRef] 
54. Kim, D.; Langmead, B.; Salzberg, S.L. HISAT: A fast spliced aligner with low memory requirements. Nat. Methods 2015, 12, 357-360. [CrossRef] [PubMed]

55. Langmead, B.; Salzberg, S.L. Fast gapped-read alignment with Bowtie2. Nat. Methods 2012, 9, 357-359. [CrossRef]

56. Li, B.; Dewey, C.N. RSEM: Accurate transcript quantification from RNA-Seq data with or without a reference genome. $B M C$ Bioinform. 2011, 12, 323. [CrossRef]

57. Wang, L.; Feng, Z.; Wang, X.; Wang, X.W.; Zhang, X.J. DEGseq: An R package for identifying differentially expressed genes from RNA-seq data. Bioinformatics 2009, 26, 136-138. [CrossRef] [PubMed]

58. Pan, X.; Welti, R.; Wang, X. Quantitative analysis of major plant hormones in crude plant extracts by high-performance liquid chromatography-mass spectrometry. Nat. Protoc. 2010, 5, 986-992. [CrossRef] [PubMed]

59. Katoh, K.; Misawa, K.; Kuma, K.; Miyata, T. MAFFT: A novel method for rapid multiple sequence alignment based on fast fourier transform. Nucleic Acids Res. 2002, 30, 3059-3066. [CrossRef]

60. Price, M.N.; Dehal, P.S.; Arkin, A.P. Fast Tree: Computing large minimum evolution trees with profiles instead of a distance matrix. Mol. Biol. Evol. 2009, 26, 1641-1650. [CrossRef] [PubMed]

61. Letunic, I.; Bork, P. Interactive Tree Of Life (iTOL) v4: Recent updates and new developments. Nucleic Acids Res. 2019, 47, W256-W259. [CrossRef] [PubMed] 